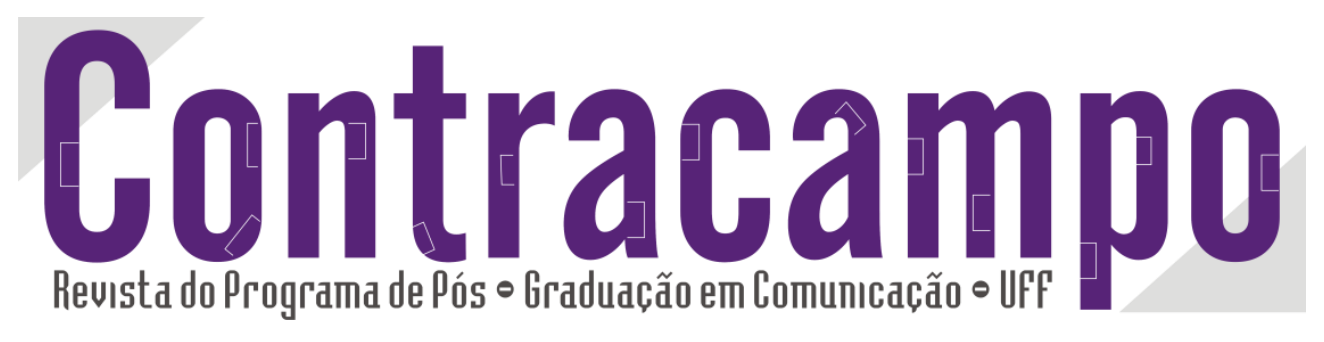

\title{
Sobre o jornalismo de revista e o seu infinito singular
}

\section{About the magazine journalism and its infinite singular}

\section{Frederico de Mello Brandão Tavares \\ fredericombtavares@yahoo.com.br}

Professor Adjunto da Universidade Federal de Ouro Preto. Doutor em Ciências da Comunicação pela Universidade do Vale do

Rio dos Sinos (UNISINOS). Bacharel e Mestre em Comunicação Social pela Universidade Federal de Minas Gerais (UFMG).

Realizou estágio de doutorado no exterior junto à Universidad Rey Juan Carlos (URJC, Madrid), Espanha.

${ }^{1}$ Versão revista e modificada de artigo apresentado no Grupo de Trabalho "Estudos de Jornalismo", do XXI Encontro da

Compós, na UFJF, Juiz de Fora, MG, em junho de 2012.

Ao citar este artigo, utilize a seguinte referência bibliográfica

TAVARES, Frederico Mello Brandão. Sobre Jornalismo de Revista e o seu infinito singular. In: Revista Contracampo, $\mathrm{n}^{\mathrm{o}}$ 25, dez. de 2012. Niterói: Contracampo, 2012. Pags: 97-116.

\section{PPGCOM $=$ UFF}

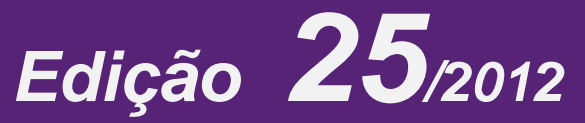

Ensaio temático "Mídia e Medo"

Contracampo

e-ISSN 2238-2577
Niterói (RJ), no25, dez/2012.

A Revista Contracampo é uma revista eletrônica do Programa de PósGraduação em Comunicação da Universidade Federal Fluminense e tem como objetivo contribuir para a reflexão crítica em torno do campo midiático, atuando como espaço de circulação da pesquisa e do pensamento acadêmico. 


\section{Resumo}

Este texto busca pensar sobre os processos que envolvem a constituição da identidade editorial de uma revista. Tendo como referente uma ampla pesquisa realizada a respeito da revista Vida Simples, publicada mensalmente pela Editora Abril, problematiza-se sobre as características e estrutura de uma publicação e como seus movimentos editoriais e comunicativos colocam em cena algumas dinâmicas metonímicas e especulares que configuram sua totalidade e que, ao mesmo tempo, oferecem elementos reflexivos para uma problematização em relação ao chamado jornalismo de revista. A principal ideia desenvolvida é de que há na revista e nas ações que a configuram editorialmente uma autorreferenciação que tende ao infinito. Um movimento que, mais que apontar uma linha de atuação temática e ideológica, dá a ver uma singularidade processual jornalística.

Palavras-chave: Jornalismo de Revista; Identidade Editorial; Singularidade.

\section{Abstract}

This text tries to think about processes involved in the formation of the identity of a magazine editorial section. Taking as a reference a broad survey about Vida Simples magazine published each month by Editora Abril, we problematize up on the characteristics and structure of a publication and how its editorial movements and communications put into play some specular and metonymic dynamics that shape its entirety and at the same time provide reflective elements to an inquiry regarding the so-called magazine journalism. The main idea developed is that there is some self-reference that tends to infinity in the magazine and in the actions that it shapes editorially. It's a movement that, rather than pointing a thematic and ideological performance line allows the visualization of a journalistic procedural singularity.

Keywords: Jornalismo de Revista; Identidade Editorial; Singularidade. 
Ser revista ad infinitum

nfinito Particular
(Marisa Monte, Arnaldo Antunes, Carlinhos Brown)

Eis o melhor e o pior de mim

$\mathrm{O}$ meu termômetro, o meu quilate

Vem, cara, me retrate

Não é impossível

Eu não sou difícil de ler

Faça sua parte

Eu sou daqui, eu não sou de Marte

Vem, cara, me repara

Não vê, tá na cara, sou porta bandeira de mim

Só não se perca ao entrar

No meu infinito particular

Em alguns instantes

Sou pequenina e também gigante

Vem, cara, se declara

O mundo é portátil

Pra quem não tem nada a esconder

Olha minha cara

É só mistério, não tem segredo

Vem cá, não tenha medo

A água é potável

Daqui você pode beber

Só não se perca ao entrar

No meu infinito particular

A letra acima abre o álbum homônimo da cantora Marisa Monte, lançado em 2006. Seu conteúdo, se realizamos uma análise rápida, traz alguns pontos interessantes. Diz, em linhas gerais, de uma espécie de convite e apresentação. O sujeito principal (a cantora, neste caso) realiza uma interlocução com um "cara". De modo ora imperativo, ora persuasivo, o/a protagonista indica suas características principais e orquestra, a partir destas, as ações que espera de seu interlocutor. Nesse jogo, que varia entre uma expectativa e uma identidade, figura, de maneira central, o paradoxo. Trechos como "Eis o melhor e o pior de mim”; "Em alguns instantes/ Sou pequenina e também gigante"; É só mistério, não tem segredo" apresentam o contexto de um "infinito particular" cercado e constituído de oscilações conflitantes e que, apesar de aparentemente complexo, "intransponível”, seria de "fácil acesso". A convocação 
realizada ao interlocutor indica o caminho para acessar tal infinitude: "Vem, cara, me retratel Não é impossível/ Eu não sou difícil de ler/ Faça sua parte”.

No que se cria e se conduz na canção, entre expectativa e identidade, dois pontos-chave, duas ideias, merecem atenção: ação e infinito. A principal ação da música pode ser sintetizada numa espécie de "revista", no sentido de revistar. Coloca-se "em revista" as características do/a protagonista, indicadas por ele/a mesmo/a e possíveis de serem alcançadas pela "revista" de um infinito realizada pelo interlocutor. Um infinito, pois, "em revista" e "revistado", cujo acesso se dá no duplo reconhecimento (entre ambos os interlocutores) de uma dinâmica própria e em constante movimento.

A letra, apesar de tratar de um universo subjetivo, traz elementos presentes em uma ideia "geral" de infinito. Essa ideia pode ser encontrada na relação entre um elemento e seu oposto - caso da música acima -, entre um elemento e um fragmento que lhe sugere semelhança, entre uma progressão ou regressão contínua, entre lógicas especulares de reflexos perpétuos ou em metonímias. E sua materialização cotidiana se dá de diversas formas. Se a música aqui citada a mostra por meio do conteúdo, sua presença em outras manifestações simbólicas, textuais e imagéticas, dimensionam, também por meio da forma e/ou por meio de processos, a composição de sentidos que a cerca. Quando explicita seu "encontro" com o infinito ao refletir sobre a "ficção que vive na ficção", Jorge Luis Borges (1986, p. 325) assim o descreve:

Debo mi primera noción del problema del infinito a una gran lata de bizcochos que dio misterio y vértigo a mi niñez. En el costado de ese objeto anormal había una escena japonesa; no recuerdo los niños o guerreros que la formaban, pero sí que en un ángulo de esa imagen la misma lata de bizcochos reaparecía con la misma figura y en ella la misma figura, y así (a lo menos, en potencia) infinitamente...

Tal imagem, na verdade, remete, segundo seus críticos, à própria ficção do autor, indicando uma influência em seu processo criativo. Em suas narrativas, o infinito é constantemente associado ao uso de jogos textuais labirínticos e especulares. Seu conhecido texto "Biblioteca de Babel", que fala de uma biblioteca infindável, com uma infinidade de livros, diz desse traço narrativo tanto pelo conteúdo quanto por aspectos formais. A capa (Fig. 1) da edição brasileira de Ficciones [Ficções], onde o texto está publicado, remete, inclusive, à descrição que o autor apresenta no parágrafo final do conto: 


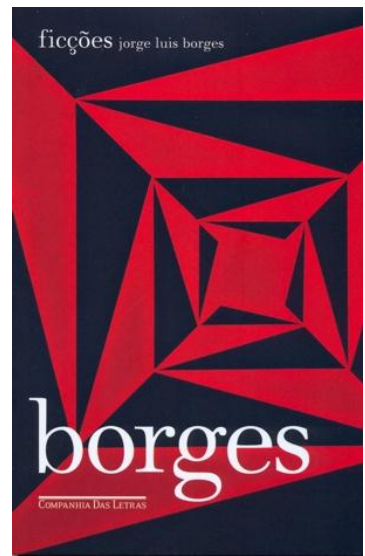

Acabo de escrever infinita. Não traduzirei esse adjetivo por um hábito retórico; digo que não é ilógico pensar que o mundo é infinito. Os que o julgam limitado postulam que em lugares remotos os corredores e escadas e hexágonos podem inconcebivelmente cessar - o que é absurdo. Os que o imaginam sem limites esquecem que não é ilimitado o número possível de livros. Eu me atrevo a insinuar esta solução do antigo problema: "A Biblioteca é ilimitada e periódica". Se um viajante eterno a atravessasse em qualquer direção, comprovaria ao cabo de séculos que os mesmos volumes se repetem na mesma desordem (que, repetida, seria uma ordem: a Ordem). Minha solidão se alegra com essa elegante esperança (BORGES, 2007, p. 78 - 79).

Fig. 1 - Capa Ficções (J.L.Borges - Ed. Cia das Letras)

A relação de Borges com o infinito (como referente e como recurso estilístico) é "apenas" um exemplo da ligação deste com o fazer narrativo. Trata-se de uma relação histórica, que pode ser observada em obras como Quixote e Ulisses, sempre citadas como referência de narrativas que se abrem a si mesmas deixando à mostra, pelos seus tempos internos, sua própria escritura. A teoria literária, com destaque para aquela iniciada no contexto do surgimento do noveau roman na França e o auge das aproximações formalista e estruturalista à literatura (ZAVALA, 2010, p. 362) a partir de meados do século passado, esteve muito atenta a essa questão.

Nesse contexto, Lucien Dällenbach (1989) retoma e atualiza a noção de mise en abyme articulada pela primeira vez por André Gide, no final do século XIX, para referir-se a recursos existentes em textos e imagens que, em sua constituição, incidem sobre si mesmos. "Cair no abismo", na tradução do francês, diz respeito à ação de movimentos narrativos na qual elementos textuais (passagens e recursos linguísticos) ou imagéticos, conteúdos e tempos, são ativados e conduzem a um meta-movimento abismal, reproduzindo-se. Uma ação que, de acordo com os nós que a permeiam, perfila um infinito especular e/ou paradoxal no interior de uma obra.

Mais que um conceito, a mise en abyme aparece também como uma ferramenta de escrita (do autor) e leitura (do leitor comum, como interpretação; e do leitor experto, como recurso metodológico) e que ajuda tanto a pensar um produto específico, percebendo sua totalidade, quanto, de maneira ampliada, a desvelar a trama que constitui esse todo em sua pluralidade. Uma "boa" mise en abyme, menos que apontar para "o" sentido de uma obra, 
indica, justamente, sua polissemia, seu não-fechamento e, consequentemente, a complexidade de sua trama.

É desse ambiente e de suas pistas que alcançamos o jornalismo. Da canção interpretada por Marisa Monte ao conceito de Lucien Dällenbach, tomados aqui como uma espécie de preâmbulo, destacamos as duas questões centrais. A ação implícita de "revistar" e a ideia do infinito. Ambas, agora, pensadas a partir de um jornalismo específico, o jornalismo de revista. Segundo Tavares e Berger (2009, p. 310), "os sentidos de revista, embora despercebidos no cotidiano, marcam pragmaticamente (mesmo que de forma inconsciente) a produção que a envolve como um produto da comunicação e do jornalismo". Etimologicamente, relembram os autores, "se dividida - 're-vista' - ou verbalizada - 'revistar' - a palavra sugere uma ação de verificação, de exame, de interpretação" (TAVARES; BERGER, 2009, p. 310).

Historicamente, a revista consolidou-se como um produto jornalístico cuja identidade foi elaborada não só no diálogo e concorrência com os outros meios, principalmente impressos, mas também no amadurecimento de um patrimônio de processos editoriais ligados a aspectos jornalísticos e também a outros institucionais e sociais. Tanto na abordagem de acontecimentos quanto na "tradução" de temáticas da vida social, a revista segmentou-se e passou a ser desenvolvida por grandes empresas e corporações, trazendo para a sua elaboração editorial um complexo fazer.

No entanto, para além disso, tomando-a como um produto "acabado" em "si mesmo", a revista "oferece" outras complexidades. Sua especificidade está marcada não só por uma identidade prevista, mas também pelos movimentos próprios e significantes que despontam de sua materialidade impressa e se oferecem concretamente como conteúdo a ser lido e com o qual se interage. Considerado o atual cenário dos meios de comunicação e uma espécie de "conjuntura da midiatização", na qual a relação sociedade e mídia ganha contornos ainda mais indissociáveis, pensar a revista e seu jornalismo é não apenas considerar lógicas desse cenário - como a autorreferencialidade, por exemplo (FAUSTO NETO, 2008) -, mas, também, os pormenores que envolvem tais lógicas quando delimitadas em uma só mídia ou, mais que isso, em um produto específico.

"Ser revista" (TAVARES, 2011a), pois, implica na composição de uma processualidade que traz, entre outras coisas, ações que dão a ver, a todo o momento, "uma revista dentro da outra" ou a "revista dentro de si mesma" e sua dinâmica infinita rumo à formulação de uma identidade. Trata-se não apenas do uso de recursos textuais ou imagéticos, mas, também, da incorporação de uma singularidade jornalística ali formada e em desenvolvimento. Um "infinito particular", que aciona e é acionado por um "jornalismo singular". A revista, como um produto, é uma "obra" diferente, cujos 
processos e aberturas têm um ponto de partida - um exemplar -, mas seu desenvolvimento toma por referência a duração no tempo e no espaço por meio de uma produção editorial regular e referencial.

Assim, ao pensarmos tais processos e as lógicas que constituem este produto (como uma unidade múltipla), a noção de infinito vem à tona e nos impele a refletir como de maneira ora metonímica, ora especular, alguns movimentos editoriais são construídos. Para além de questões conteudísticas e ideológicas, muitas vezes foco de uma análise editorial, certos movimentos podem ser percebidos no desvelar da construção periódica de uma publicação e de sua leitura.

O presente texto propõe, ele mesmo, realizar um movimento reflexivo. Relata uma pesquisa e, ao relatá-la, agrega a ela novos elementos, incidindo reflexões sobre reflexões. Partindo de dados presentes numa pesquisa mais ampla sobre a revista Vida Simples da Editora Abril (TAVARES, 2011a), que analisou 108 exemplares da publicação - de seu surgimento em agosto de 2002 até março de 2011, incluindo cinco edições extras de periodicidade espaçada pensa-se o desenvolvimento da revista a partir de seus elementos editoriais refletidos em suas páginas ao longo do tempo e, simultaneamente, reflete-se sobre, na divisão ou multiplicação de sua unidade, os processos que unificam essa dispersão, indicando sua complexidade e a de seu jornalismo.

Identidade Editorial para além do estilo e da missão

Juarez Bahia (2009) afirma que há um estilo próprio na "maneira de ser" de um meio de comunicação. "Os seus significados envolvem aspectos de ritmo, jeito, equilíbrio, linguagem, apresentação, símbolos, ética e personalidade" (BAHIA, 2009, p. 95). A reflexão do autor está baseada na existência de um "estilo jornalístico", uma espécie de padrão que atravessaria os produtos noticiosos, não sendo uma qualidade única e fixa, idêntica em todas suas as manifestações, mas uma ferramenta intrínseca à sua produção.

A maneira de ser e o padrão de estilo não querem dizer que um veículo seja objeto de uma camisa-de-força. Normas estilísticas só devem ser invioláveis na restrição a abusos de linguagem ou a vícios e 
imprecisões que comprometem irremediavelmente a percepção da mensagem (BAHIA, 2009, p. 97).

Bahia (2009) faz menção aos muitos "Manuais de Redação e Estilo" no que se refere à busca por um estilo a partir de uma unidade focada na legibilidade e identidade dos discursos que estarão presentes em um só veículo de comunicação. É verdade que, em tais manuais, há uma série de instruções e normas que indicam, de maneira concreta, formas de se alcançar a tal unidade pretendida, sendo essa, num "todo", diretamente responsável pela "linha editorial" de uma publicação (no caso da imprensa, por exemplo). Nos manuais há a busca por fórmulas consensuais de jornalismo, tendo como foco o texto (BAHIA, 2009), mesmo que no processo de sua feitura, a começar pelo próprio contato dos jornalistas com os manuais, existam descompassos e desajustes (BRONOSKY, 2008).

$\mathrm{Na}$ imprensa, indo além do texto para pensar o estilo, se tomamos em conta o "ser" de um veículo a partir de sua linha editorial, aquela que diz não apenas de uma linguagem, mas de todo um conjunto, as palavras de Fátima Ali (2009, p. 47) sobre a "missão editorial" de uma revista são interessantes:

Você sabe o que é missão editorial? Como na música de Zeca Pagodinho, a maioria dos jornalistas numa redação poderia responder "nunca vi, nem comi, eu só ouço falar". Muitas revistas não têm missão definida ou explícita, e, quando têm, limitam-se a incluí-la nos materiais de venda de publicidade. A missão é chamada, entre outras coisas, de objetivo ou filosofia editorial. Há quem chame de nada. Com qualquer nome ou nome nenhum, uma coisa é certa: se você não sabe dizer o que é a sua revista numa frase concisa ou num parágrafo curto, você não sabe o que é a sua revista.

As questões tratadas por Bahia (2009) e Ali (2009), apesar de focos distintos para pensar um veículo - a primeira lida com uma técnica e a segunda com um propósito -, quando unidas, chamam a atenção para um aspecto: ao focarmos uma revista e investigarmos sua linguagem, ou olharmos para uma revista sob a lupa da missão editorial, parece haver algo que liga ambas as visadas e que ultrapassa a concretude dos pontos de partida que se oferecem como empiria para alcançar a "identidade" de uma publicação. Se a linguagem possui um fio técnico e normativo e a missão um fio conceitual, esse fio, em ambas, é entrelaçado por outros fios. Invisíveis e 
passíveis de serem apreendidos quando se observa toda a trama que eles costuram, uma tessitura processual por eles constituída, e da qual eles são, também, elemento.

Em Vida Simples, objeto e universo de referência desse texto, temos uma "normatividade" técnica e ideológica, prevista por uma Editora, temos uma missão editorial definida, e uma grande temática (a qualidade de vida), que convoca tais esferas para um tensionamento, cujo resultado materializa-se na "totalidade" da publicação. Mas seus fios invisíveis, sua trama processual, faz-se complexa. Tanto pela maneira como os processos entrelaçam essa "totalidade" quanto pela própria complexidade jornalística que eles configuram ${ }^{1}$, compondo uma especialidade da revista e de sua "revistação"2.

No interior do corpus analisado e na construção de uma série de recortes buscamos pensar "o todo" da revista através de suas partes e conexões. Considerando as “estruturas" de Vida Simples, analisamos seu projeto editorial, seu projeto gráfico e seus temas (da qualidade de vida) ${ }^{3}$. Por meio de uma análise de conteúdo e de uma análise textual e visual, cruzada a autores que analisam questões editoriais, jornalísticas e gráficas, observamos a configuração dos processos editoriais da publicação e, simultaneamente, os processos que são gerados na relação entre estes elementos, possibilitando o surgimento de especificidades que marcam a singularidade da revista. Estudamos o documento editorial que explica a revista (elaborado pela Editora) e suas seções, analisamos os exemplares das muitas edições e o diálogo de sua estrutura com o conjunto e características das diversas fases editoriais da revista, identificando-as. Também analisamos o fluxo de conteúdos ao longo de 108 edições, observando como os temas vão e voltam ao longo dos textos e seções, criando um círculo temático intermitente que enquadra os assuntos e ajuda a revista a constituir uma identidade e

\footnotetext{
${ }^{1} \mathrm{E}$ interpretar tal trama, reconhecendo sua tessitura, é, assim como em uma narrativa, "destecer a trama textual e vir simultaneamente tecendo um novo tecido com os fios extraídos de outros tecidos-textos, havendo, assim, o duplo gesto de desconstrução / construção" (GARCIA, 2008, p. 129).

${ }^{2}$ Termo desenvolvido em Tavares (2011a) para tratar do processo comunicativo e editorial da revista Vida Simples. Pode-se assim explicá-lo: “A ideia de uma 'revistação' vem da necessidade de sintetizar e/ou nomear, em um termo, a complexidade que compõe a globalidade que envolve a revista, permitindo, ao mesmo tempo, abranger o que lhe é próprio. Um neologismo criado para referir-se a uma ação que, partindo da revista enquanto meio de comunicação, caracterizaria o seu processo comunicativo e jornalístico. Nesse sentido, tomamos como 'revistação' (revista + ação - em sentido substantivado) aquilo que 'faz funcionar', a partir da revista, um circuito que abrange uma tessitura constituída entre produto, práticas, referentes e interlocutores" (TAVARES, 2011b, p. 235).

${ }^{3}$ Dados dessa análise e visualizações sobre o corpus podem ser vistas em Autor (2011) e acessadas em http://mdemulher.abril.com.br/revistas/vidasimples/edicoes/
} 
uma especialidade no sentido de uma especialização jornalística e de uma cobertura segmentada.

Pelo discurso da própria revista, também nos atentamos para as maneiras como sua dimensão "projetual" e sua temática principal ganham vida em sua materialização mensal, analisando os editoriais, as cartas escritas aos leitores. E, por fim, analisamos as 108 capas das edições estudadas, apontando tanto para a configuração de um conceito editorial quanto para a formulação de uma estética para tratar jornalisticamente da qualidade de vida e do bem-estar na sociedade.

A partir dos achados, podemos dizer: em Vida Simples há uma complexidade que marca sua singularidade. Uma complexidade que a precede e que, ao mesmo tempo, procede dela mesma. Uma complexidade processual e constituinte.

\section{Uma complexidade pelos processos}

Ao afirmar a ideia de complexidade a partir do amor, Edgar Morin (2001) lembra o significado do "complexo" e traz alguns aspectos para pensarmos a complexidade aqui focada, "revistativa" e de Vida Simples. Em seu sentido literal, complexo vem de complexus, "aquilo que se tece em conjunto". Assim, se o amor é um complexo, ele

é algo único, como uma tapeçaria que é tecida com fios extremamente diversos, de origens diferentes. Por trás de um único e evidente "eu te amo" há uma multiplicidade de componentes, e é justamente a associação destes componentes inteiramente diversos que faz a coerência do "eu te amo" (MORIN, 2001, p. 16).

Atribuir complexidade ao amor, diz Morin (2001), requer um olhar poliocular, capaz de observar e relacionar ingredientes físicos, biológicos, antropológicomitológicos que irão se reunir e se cristalizar. Não é possível tomá-los em separado, mas percebê-los em movimento, formando um todo no qual uma face terá elementos da outra, um aspecto só poderá o ser no conjunto que ele forma com seus pares; o que não significa uma junção harmônica, mas uma espécie de fricção contínua. Um processo que nos endereça alguns aspectos para pensar "nossa" complexidade específica, cuja ação

\footnotetext{
${ }^{4}$ Expressão desenvolvida em TAVARES (2011) para tratar da ideia de um jornalismo impresso e próprio do meio revista.
} 
processual que a gera e é por ela gerada relaciona-se a um "ser revista" a partir de uma "revistação" friccionada por uma série de ingredientes.

Ao refletir sobre os processos que habitam o amor (uma ação sobre e do amor), Morin lembra que este, "assim como tudo o que é vivo e humano", "encontra-se submetido ao segundo princípio da termodinâmica, que se define como um princípio de degradação e desintegração universais" (p. 24). O amor só vive, reforça o autor, renascendo incessantemente; "o amor implica a regeneração permanente do amor nascente" (MORIN, 2001, p. 24). Na ação que permeia o amor, portanto, há um paradoxo constante, pois, como ressalta Morin (2001, p. 25),

o amor é paradoxal como a vida e, por isso, há amores que duram, do mesmo modo que dura uma vida. Vive-se de morte, morre-se de vida. $\mathrm{O}$ amor poderia, potencialmente, regenerar-se, operar em si mesmo uma dialógica entre a prosa que se espalha na vida cotidiana e a poesia que fornece seiva a essa mesma vida.

Relacionando o pensamento do autor e seu paradigma da complexidade ao Jornalismo, Fontcuberta (2006) remete a ideia do complexo à união entre o único e o múltiplo e critica a maioria dos meios de comunicação. Seriam estes fontes de um jornalismo que não se adequou à complexidade do mundo e que prefere a simplificação como ferramenta para lidar com os temas e fatos que dela emergem. A autora admite que grande parte da mídia não reconhece a existência simultânea de uma multiplicidade e uma unicidade nos elementos da realidade. Os meios estariam regidos por um princípio de simplicidade que separa o que está junto (realizando uma disjunção) ou então unifica o que é diverso (realizando uma redução), operando, ao fim, uma distorção em sua leitura sobre o mundo.

Fontcuberta (2006) chega a propor um tipo de sistema jornalístico que fuja a esse paradigma simplificador, contrapondo-o a um modelo anterior de jornalismo, não adaptado às novas exigências do mundo complexo e de leitores também complexos. Em outras palavras, ela formula um sistema que, sob esse ponto de vista, daria conta de novos modelos interacionais em vigência na sociedade.

Todo esse conjunto de reflexões, que traz à nossa discussão as proposições sobre o complexo e a presença deste no Jornalismo, quando tensionado à realidade de Vida Simples, permite-nos pensar sobre sua complexidade. Não sendo nossa intenção 
aqui julgar as estratégias da revista em relação a uma apreensão complexa do mundo, ganham destaque algumas questões: como trazer a complexidade para o interior da "simplicidade" proposta pela revista? Como, ao falar de uma "vida simples", tem-se um jornalismo complexo? As respostas para tais perguntas encontram-se, justamente, na compreensão sobre por onde passa o complexo da revista e na revista. Em outras palavras, sob o nosso ponto de vista, encontram-se na compreensão sobre suas "ações" e como estas conduzem uma espécie de "infinito singular", correspondente a um "nascer" e um "morrer", um movimento paradoxal - temático, estético e comunicacional - que conduz uma espécie de "devir editorial".

Afirmar uma complexidade de Vida Simples (e, de certa forma, do jornalismo de revista em geral) não significa, nesse sentido, propor que tal jornalismo seja uma espécie de exceção - para pensar a reflexão de Fontcuberta (2006) - em relação àquele praticado por outros meios, realizando, pois, uma abordagem englobante de seus conteúdos, falando de maneira complexa sobre a qualidade de vida (e os temas do mundo), colocando-a "em revista" e construindo parâmetros "aprofundados" e "totais" sobre o bem viver na contemporaneidade.

É verdade que, assim como qualquer revista, Vida Simples assume para si um papel jornalístico de cumprir certas "funções culturais mais complexas que a simples transmissão de notícia" (SCALZO, 2004), pelo menos se consideramos o "fazer notícia" como um a priori jornalístico que difere, pelo caráter do veículo, os níveis de aprofundamento sobre um certo assunto. No entanto, sem avaliar as condições do saber que ela produz em relação às temáticas que aborda e sem compará-lo àquele produzido por outros meios e veículos (que também podem realizar um olhar complexo sobre o mundo e as temáticas da "nossa" revista), pode-se dizer que, identificando ações e, nesse sentido, os processos de constituição de um significado editorial de qualidade de vida, é possível pensar "o" complexo de Vida Simples, relembrando tanto a mirada “poliocular" proposta por Morin (2001) quanto sua reflexão sobre a ação que perpassa o amor.

É nesse sentido que "ser revista" e "viver bem" (considerando a qualidade de vida proposta), entrecruzando, desde uma lógica "revistativa", assuntos referentes a uma temática múltipla - a qualidade de vida -, leva a uma "revistação" (TAVARES, 2011a), uma ação jornalística complexa, permeada por movimentos intrínsecos e extrínsecos à 
revista. Ambiência essa relacionada à globalidade de Vida Simples e aos sentidos que se vêem acionados pela complexidade que a envolve em um movimento de progressão e regressão, que tende, de maneira aberta (jogo entre produção e recepção e entre um exemplar e um conjunto deles) e ao mesmo tempo autorreferencial, a si mesma e à sua "identidade em constituição".

\section{Mise en abyme e o "abismo" de Vida Simples}

Um poema (Fig. 2) presente na seção “Outras Palavras" da edição 46, de outubro de 2006, encerra aquela edição e, ao mesmo tempo, funciona como metáfora para pensarmos o "tecido conjunto" de Vida Simples, onde uma série de elementos ganham vida (ora falando da revista em geral, um todo pela parte; ora falando de Vida Simples em particular, no sentido de uma parte pelo todo).

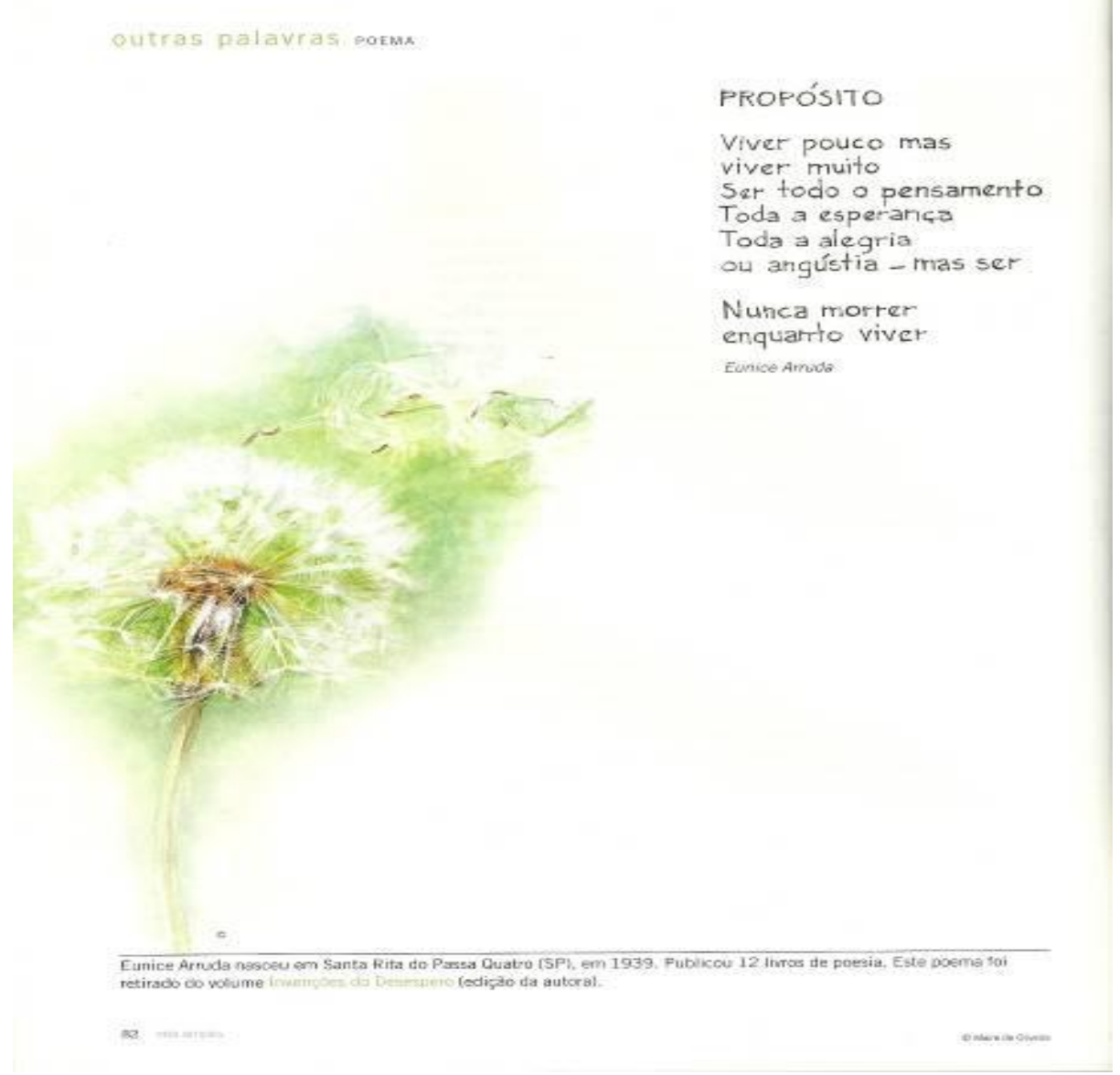

Fig. 2 - Seção "Outras Palavras" - Vida Simples, Ed. 46 (out. 2006) 
Se o amor é tal qual a lógica do viver humano (MORIN, 2001), paradoxal por viver numa permanente impermanência, assim também é o "ser revista" e aquilo que permite seu regimento (no sentido do existir aquilo que a rege): sua ação própria. $\mathrm{O}$ poema de Eunice Arruda, intitulado "Propósito", fala de vida, fala de ser, fala de morte. Lembra o contraponto entre o viver e o morrer, do qual fala Morin (2001) e traz a dupla questão que perpassa Vida Simples, desde onde a complexidade emerge como terceiro constituinte. "Ser revista e viver bem", duplo que orienta a análise que realizamos, diz respeito a uma vida que é da revista e a um viver que é o da qualidade de vida. E ambos se conectam a partir de uma complexidade processual que os precede e que deles procede, inaugurando e reinaugurando, a cada nova edição, a permanente impermanência de seus temas e de seu jornalismo, cujo encontro permite tanto a intermitência (temática e estética) quanto a regularidade (modo de fazer e estrutura) ${ }^{5}$.

Em Vida Simples, pois, há, sim, uma tentativa de realizar interpretações sobre a realidade social, uma vez que estamos falando de reportagens e materiais jornalísticos em uma revista especializada e segmentada. Há, também, ligado a uma prática, a um fazer, um conjunto que diz respeito a uma materialidade (as maneiras como o meio relaciona-se com o tema na paginação e na forma de texto e imagem, assim como na configuração de suas seções fixas e esporádicas), bem como a um relacionar-se particular com um público previsto e suas respectivas demandas. Mas, mais que isso, na junção de ambos os processos, há, na globalidade da revista e de seus sentidos, algo específico, o seu processo de "revistação" ele mesmo. Um processo editorial que orienta uma identidade e, ao mesmo tempo é por ela orientado. Um processo aberto, permeado de incompletudes, e que diz de um conhecimento, neste caso, não apenas cognitivo ${ }^{6}$. Processo que ultrapassa uma só edição, única, mas que pode, sobre ela, ser projetado e observado, desde a sua tessitura. Um tecido, portanto, que está tramado por um conjunto de fatores que dizem respeito a um todo (o total de edições e um modo de ser "revistativo" que as rege), cuja unicidade é múltipla (formada por aquilo que cada

\footnotetext{
${ }^{5}$ Pelas intermitências temáticas e estéticas que permeiam sua constituição ao longo de suas edições e em uma só edição, bem como pelos diálogos institucionais e sociais que nelas podem ser percebidos, constituem-se movimentos editoriais que elaboram uma espécie de coerência paradoxalmente prevista e involuntária. Pensada por um projeto editorial e materializada naquilo que a ele se agrega no processo contínuo de editoração. Ver mais em Tavares (2011a e 2011 b).

${ }^{6}$ Em Tavares (Ibidem) apontamos para a existência de aspectos sensíveis, pouco táteis (SODRÉ, 2006), na costura editorial e na cobertura dos temas na e pela revista.
} 
edição, como um todo múltiplo, agrega a esse outro todo maior) e incompleta, por isso em movimento no tempo e no espaço, regida por tensões editoriais, jornalísticas, temáticas.

Olhando para o poema através da lupa dos processos e, por isso, na possível afirmação de que nele há uma convergência em relação à singularidade da revista, é como se o poema (Fig. 2), de maneira indiretamente metalinguística, explicasse a revista dentro dela mesma. Não a revista como produto, mas aquilo que a constitui enquanto ação, desde onde seus processos são acionados, tornando-a, dessa maneira, uma "totalidade".

Assim, o que prevalece na revista é a ação e, consequentemente, o que se modifica de maneira reflexiva. "Ser revista" é jornalisticamente operar sobre o mundo dentro de uma lógica que abarca racionalidades e as põe em movimento. Uma construção, mas não somente. Uma realidade, mas não somente. Tampouco somente uma essência (GRÖTH, 2006). Mas uma constituição. Um pronto que não está feito e que, dentro do seu próprio universo de uma completa incompletude, baseado numa espécie de autorreflexidade, ruma ao infinito, mudando sem deixar de ser, portanto. A revista dentro dela mesma, mensalmente, reverberando o diferente para, ao fim, ser ela própria, "regenerando-se" continuamente em sua identidade difusa e móvel, regular e paradoxal, numa espécie de "mise en abyme revistativa"7. Um "abismo" que, em Vida Simples, dá sentido - às vezes de forma antitética - a seus processos e marca, em seu devir, "sua qualidade de vida" e sua "vida simples 'revistativa". Ou seja, sua identidade editorial.

Cada parte investigada da publicação, quando observada em seus detalhes, deixa à mostra lógicas especulares e metonímicas de uma mise en abyme cuja multiplicidade, assim como em uma narrativa, "oferece-se como blocos de significação que, se desunidos, desarticulam a complexa rede de relações, onde cada unidade é um nó, assinalando o cruzamento de cadeias significativas diversas" (GARCIA, 2008, p. 129). E o conjunto de tais partes compõe esse mesmo todo que se encontra refletido em tais fragmentos.

A metáfora abismal, dessa forma, mais que apontar para uma só revista (Vida Simples), diz também da possibilidade de se pensar desconstruções e suas reestruturações reflexivas, conscientes e inconscientes, para a compreensão de identidades editoriais no jornalismo de revista. Algo que remete à sua singularidade.

\footnotetext{
${ }^{7} \mathrm{Na}$ conceituação de Dällenbach (1989, p. 42), “[...] the common root of every mise en abyme is clearly the idea of reflexivity, and this will provide our first identifying property".
} 
O jornalismo de revista e seu infinito singular

Nos estudos brasileiros, uma das mais recorrentes afirmações do singular no jornalismo vem da reflexão de Adelmo Genro Filho (1987) a partir da revisão crítica da estética de Lukács.

A preocupação com a singularidade dos fatos ou pela especificidade, como se diz mais comumente, é marca dos bons repórteres ou redatores. No entanto, essa questão não é tratada do ponto de vista teórico, uma vez que a singularidade (que seria o objeto do jornalismo) é entendida no sentido vulgar, não filosófico, com base no senso comum que, via de regra, percebe o fundamento da realidade como uma soma ou agregado de coisas ou eventos singulares, ao invés de percebê-lo também em suas dimensões concretas de particularidade (GENRO FILHO, 1987, p. 155).

O pensamento do autor retoma, além da ideia de singularidade, a necessidade de se pensar esta em relação à universalidade e particularidade, tomando as três esferas indissociáveis para uma leitura da realidade que fuja de uma "ideologia burguesa" e que consiga olhar o real como um todo que não seja apenas um agregado de partes, de fenômenos destituídos de nexos históricos e dialéticos. Na proposição do autor, perpassa uma defesa em função do jornalismo como área que

uma vez que inaugura historicamente uma nova possibilidade epistemológica, uma teoria capaz de abrangê-lo deve propor claramente o problema em sua conexão com categorias filosóficas, situando os aspectos histórico-sociais no contexto de uma reflexão de alcance ontológico sobre o desenvolvimento social (GENRO FILHO, 1987, p. 156).

Na leitura que realiza da estética de Lukács, Genro Filho (1987, p. 159 - 160) propõe que as categorias utilizadas pelo filósofo (singular, particular e universal) são fecundas para "caracterizar as representações que se referem estritamente a formas de

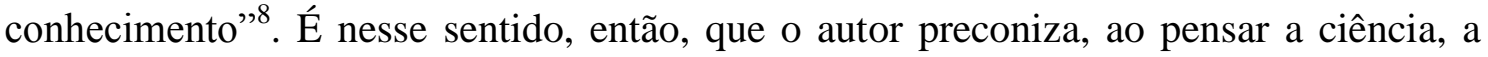

\footnotetext{
8 “Ao contrário do que ocorre em relação à arte, essas categorias podem fornecer o axioma teórico para uma teoria do jornalismo. Os conceitos de singular, particular e universal expressam dimensões reais da objetividade e, por isso, representam conexões lógicas fundamentais do pensamento, capazes de dar
} 
arte e o jornalismo, diferenciando-os no trato a partir de tais categorias, que a singularidade no jornalismo "[...] além de não ser arbitrária, é um ponto de chegada que coincide com a superação do particular e do universal, que sobrevivem enquanto significados no corpo da notícia e sob a égide do singular" (GENRO FILHO, 1987, p. 161).

Dada essa presença no interior da notícia e esse filtro pela singularidade, no jornalismo noticioso, "em cada acontecimento, uma infinidade de fatos podem ser construídos pelo jornalismo" (TEIXEIRA, 2007, p. 24); mas, para que se garanta uma "boa cobertura", é essencial que, em cada notícia, o singular de cada referente seja contextualizado através do particular (TEIXEIRA, 2007). Ou seja, é na capacidade de contextualização que reside a "qualidade jornalística". Não uma busca pelo singular, mas a compreensão de que o mesmo só pode ser obtido se reconhecido como em relação com o universal e o particular. Movimento este que indicaria a possibilidade de apreensão da complexidade do fenômeno a ser relatado, fugindo de um movimento outro, "ruim", baseado na sobreposição natural de causas e consequências.

Não trazendo as categorias explicadas e propostas por Genro Filho (1987) para a esfera do conhecimento propriamente dito produzido por Vida Simples em relação à qualidade de vida, realizando uma visada crítica sobre seus textos e conteúdos, mas pensando tais categorias em relação ao "ser revista" (que incidirá, pois, sobre estes conteúdos), alguns pontos se definem e podem ser afirmados. Podemos dizer que Vida Simples incorpora universalmente qualidades "revistativas" - que formatam um tipo de jornalismo -, possui abordagens referentes a um segmento "particular" de jornalismo voltado para a qualidade de vida -, e, ao mesmo tempo, em sua singularidade, sua maneira de ser, diferencia-se do universal e do particular, possuindo, de ambos, alguns elementos.

Há na publicação um composto cuja globalidade gira em torno de uma lógica editorial ampla e complexa, passível de ser captada desde o produto. Uma dinâmica que se vale de processos previstos e que, no jogo com as processualidades (o ser dos e pelos processos) que a permeiam, advindas da indissocialidade entre sua produção, seus referentes temáticos (e daquilo que nestes mobiliza certas abordagens) e seus interlocutores, vê-se acionada e transformada jornalística e comunicacionalmente. Um 
todo, portanto, processual e complexo que está em Vida Simples. É desse todo que desponta uma singularidade editorial e um jornalismo singular feito "para" e "a partir" dela e que, de alguma forma, permite "contextualizar" o jornalismo de revista.

E, também, é desse todo móvel que a partir de uma revista propõe-se viver bem. A qualidade de vida de Vida Simples é a de uma vida simples jornalística e "revistativa", cujo simples é costurado pelo que nela há de "revistativo", de simplicidade (enquanto um significado de uma vida simples) e daquilo que emerge do encontro de ambos, dando a ver o que lhe há de singular. Uma "revistação do bem viver" processual e relacional. Em processo e que se relaciona a questões específicas, a realidades específicas (sociais e "revistativas") e, pelos imbricamentos que promove, oferece um caminho de apreensão jornalística do mundo, constituindo uma complexidade reflexiva.

Um apaixonado por revistas, o editor espanhol Juan Caño (1999), ao falar sobre a "revista em processo", cuja estrutura muda, mas sem perder sua identidade, afirma: "uma revista muda o tempo todo para ser ela mesma". Borges (2007), quando falava da suspeita humana sobre uma duplicidade ilusória do espelho da "Biblioteca de Babel", dizia preferir "sonhar que as superfícies polidas figuram e promovem o infinito" (p. 69).

Transpondo tais dizeres para o "infinito" de Vida Simples e as reflexividades que o compõem é interessante pensar como a singularidade jornalística composta pelo conjunto de seus processos e jogos editoriais pode ser associada a outros "abismos" e outras identidades. Revistas distintas e seus distintos jornalismos têm (e terão) sua vitalidade a partir de outros - e próprios - entornos comunicativos que os envolvem e que engendram suas globalidades. E a percepção sobre esse "ser revista" e sua tal "revistação", em sua processualidade mais ampla (editorial, jornalística e social), é que poderá conduzir para o desvelamento desses outros "todos em constituição" que eles ajudam, de forma infinita e singular, a constituir.

\section{Referências bibliográficas}

ALI, Fátima. A arte de editar revistas. São Paulo: Companhia Editora Nacional, 2009.

BAHIA, Juarez. Jornal, História e Técnica: as técnicas do jornalismo. Vol. 2. 5. ed. Rio de Janeiro: Mauad X, 2009. 
BORGES, Jorge Luis. "O aleph". In: BORGES, Jorge Luis. O aleph. São Paulo: Cia das Letras, 2008. p. $136-153$.

BORGES, Jorge Luis. “A biblioteca de babel”. In: BORGES, Jorge Luis. Ficç̧ões. São Paulo: Cia das Letras, 2007. p. $69-79$.

BORGES, Jorge Luis Borges. "Cuando la ficción vive en la ficción". In: Textos cautivos, ensayos y reseñas. “El Hogar”. Barcelona: Tusquets, 1986.

BRONOSKY, Marcelo Engels. (Quase) Tudo sobre controle: Estratégias de apropriação de manuais de redação por jornalistas em periódicos diários. 195 f. Tese (Doutorado em Ciências da Comunicação) - Universidade do Vale do Rio dos Sinos. São Leopoldo, RS, 2008.

CAÑO, Juan. Revistas: una historia de amor y un decálogo. Madrid: Editorial Eresma e Celeste Ediciones, 1999.

DÄLLENBACH, Lucien. The Mirror in the Text. Chicago: University of Chicago Press, 1989.

FAUSTO NETO, A. Notas sobre as estratégias de celebração e consagração do jornalismo. Estudos em jornalismo e mídia. Ano V, nº 1. Florianópolis: Insular, 2008.

FONTCUBERTA, Mar de; BORRAT, Hector. Periódicos: sistemas complejos, narradores en interacción. Buenos Aires: La Crujía, 2006.

GARCIA, Maria José Ladeira Garcia. A mise en abyme em inventário do inútil de Elias José. In: Verbo de Minas: letras, p.127 - p.138, Juiz de Fora, v. 7, n. 13, jan./jun. 2008.

GENRO FILHO, Adelmo. O segredo da pirâmide: para uma teoria marxista do jornalismo. Porto Alegre: Tchê, 1987.

GRÖTH, Otto. Tarefas da pesquisa da ciência da cultura. In: MAROCCO, Beatriz; BERGER, Christa. A era glacial do jornalismo: teorias sociais da imprensa. Porto Alegre: Sulina, 2006. p. $182-306$.

MORIN, Edgar. Amor, poesia e sabedoria. 3.ed. Rio de Janeiro: Bertrand Brasil, 2001.

SCALZO, Marília. Jornalismo de Revista. 2. ed. São Paulo: Contexto, 2004.

SODRÉ, Muniz. As estratégias sensíveis: afeto, mídia e política. Petrópolis: Vozes, 2006.

TAVARES, Frederico de Mello Brandão; BERGER, Christa. Revista (Verbete). In: Ciro Marcondes Filho. (Org.). Dicionário da Comunicação. Paulus: São Paulo, 2009, v. 1, p. 310 311.

TAVARES, Frederico de Mello Brandão. Ser revista e viver bem: um estudo de jornalismo a partir de Vida Simples. 468 f. Tese (Doutorado em Ciências da Comunicação) - Universidade do Vale do Rio dos Sinos. São Leopoldo, RS, 2011a.

A revista por ela mesma: visadas e propostas teóricas sobre um modo de ser

jornalismo. In: Beatriz Dornelles; Carlos Gerbase. (Org.). Papel e película queimam 
depressa: como o cinema e o jornalismo impresso tentam escapar da fogueira midiática do novo século. 1ed. Porto Alegre: EDIPUCRS, 2011b. p. 220-241..

TEIXEIRA, Tattiana. O Segredo da Pirâmide, 20 anos depois. In: AMARAL, Marcia Franz. Olhares sobre o jornalismo: a contribuição de Adelmo Genro Filho. Santa Maria: FACOS, 2007. p. $19-36$.

ZAVALA, Lauro. "Leer metaficción es una actividad riesgosa". Literatura: teoría, historia, crítica $\cdot$ n. ${ }^{\circ} 12$, p. 353 - 369, Bogotá, octubre 2010. 